\title{
PAIN AND DEATH: POLITICS, AESTHETICS, LEGALITIES
}

\author{
CAROLYN STRANGE
}

The violence of punishment and war, timeless phenomena, became freshly public at the turn of the twenty-first century: violence intended to cause pain and death has appeared in disturbing new ways, through live satellite feeds, mobile-phone videos and Internet postings, giving a false sense of omniscience and a heightened impression of global insecurity. These representations are powerful reminders that while politics and law may set the boundaries of sanctioned violence within and between states, their understanding and meanings are invariably conditioned by aesthetic questions.

Images and stories of brutalised bodies may produce suffering, disgust or empathy, but how do they do so, and to what effect? Under what circumstances does evidence of pain and death register as nothing but statistics? And if the juridical and political are imperfect tools for the acknowledgement of suffering, does art provide more effectual mechanisms?

Through essays, images, streaming video and a soundscape, the works in this volume address these questions. They follow a conference held at the Centre for Cross-Cultural Research, The Australian National University, in December 2005: 'Pain and Death: Politics, Aesthetics, Legalities'. Inspired in part by the early phase of the so-called war on terror, when pic- tures of the penal excesses it unleashed initially created embarrassment and shame, the event incorporated the work of scholars, artists and performers. In keeping with this brief, the conference call-for-papers was produced as a commercial that incorporates musical, visual and written texts:

http://www.anu.edu.au/culture/painanddeath/commercial.php

This volume's contributors move beyond the specifics of the war on terror to consider other instances in which officially legitimated violence has been invoked, contested or suppressed, not only through legal and political means, and in official records, but also in popular media and art forms.

State violence is perhaps most keenly imagined when it touches the individual, whose story can be told compellingly as both intimate and universal. This is the executing state's dilemma — the death penalty is a symbolic assault on crime and an actual attack on a body rendered vulnerable, and thus potentially an object of pity. Consequently there is no monopoly on penal symbolism. As Rosanne Kennedy shows, the death penalty, even in places where it is carried out behind prison walls, is mediated through a range of aesthetic forms, which draw on tropes and generic conventions to narrate individuals' stories 
of crime and punishment. Representations of death-penalty cases can stimulate sentiments as well as political controversies and legal interrogations, yet how that capacity is fulfilled, if at all, cannot reliably be predicted. By comparing two such cases, one from 1923 and one from 2005, she highlights the volatility of sentimentalisation as a political strategy intended to solicit sympathy for victims of capital punishment. In contrast, principled legal arguments against the death penalty provide steadier yet drier ground.

The everyday pains of punishment and the prospect of death due to conditions of incarceration, rather than intentional execution, are far less thoroughly documented. They remain largely in-house and unknown to outsiders. Prison guards pictured in the scandalous Abu Ghraib pictures were in many cases not soldiers but workers contracted on the basis of their prior experience in U.S. prisons. Although prosecutions isolated a few individuals as ring leaders and chief instigators, it was only prisoners' rights organisations and prison abolitionists that attempted, with little success, to channel public disgust toward similar penal regimes prevalent in U.S. prisons. Ethan Blue disturbs the silence over penal violence by focusing on a critical period in the history of Texas prisons, which modified, rather than eliminated, the tortuous labour of slavery and the ghastliness of lynching over the 1930s. Unlike the other essayists, he has no pictures or videos or sheaves of news reports to pore over. The illnesses and deaths produced through disease, beatings, inmate violence, exhaustion and dietary insufficiency appeared in aggregate, in the columns of annual reports. Executions only occasionally made the news, though typically in stories about condemned men's final meals. Requests for bowls of ice cream and multiple pieces of pie were not last-minute indulgences, Blue argues: they were parting gestures of generosity toward their fellow condemned men who inherited the leftovers.

If due process as practised in democracies offers little protection from pain, unbridled horror crouches close to the rule of law, eager to trespass. In the shadowland between state-sanctioned and unauthorised acts, death flourishes when violent non-state actors concentrate power. In Rwanda, paramilitary forces, although ancillary to the state militia, allowed the Hutu-led government and its supporters to slaughter hundreds of thousands of Tutsis and moderate Hutus. Unlike the sober and hidden performances of individual executions, these killings were openly profligate. Debjani Ganguly explores how these extraordinary works of death have inspired works of art, not only memorial interpretations of the genocide but novels, memoirs, dramas, documentaries and dance performances. By engaging the senses and addressing human experience through a 'trauma aesthetic', art inspired by such events, in particular the film Hotel Rwanda and the docu-fictional novel $A$ Sunday at the Pool in Kigali, defies abstract or legalistic reasoning. But aestheticising pain and death forces acknowledgement of the limits of representation. No documentary or fictional account of the genocide can convey its full terror; yet art offers, and Ganguly urges it to provide, not a trick of identification but the hope of insight into 'our collective precariousness'. 
Textile artist Monique Van-Nieuwland puts form to this insight in a work of conceptual art. A funeral-home body bag is her medium of expression. By punching impressions of national flags into the plastic, she creates a bleached-out global flag, which hangs for the bodies sacrificed in the service of war. In a powerful reminder of 'the unknown soldier', she traces a sacrificial victim with the outline of a body - her own 19-year-old son.

A complementary work, composed with the less emotive fabric of linen handkerchiefs, is charged with meaning, nonetheless, with names stitched and printed on them. They identify those who lost their lives in republican and loyalist paramilitary conflict and through the actions of the British military in Ireland. In recent years the 'Troubles' have been subdued through political and legal processes but absent victims continue to haunt the reconciliation process. Naming these individuals, many of them bystanders caught physically and metaphorically in crossfire, brings them to life in Lycia Trouton's mobile memorial and in Tom Fitzgerald's soundscape. ${ }^{1}$ The linen memorial invites reflection and incorporates site-specific mementos left by visitors. As air flows through 400 handkerchiefs, the sounds of 'The Seeming Insanity of Forgiveness' create different currents, shivering with shrieks and cries. A child's voice recites the names of the dead. A bell tolls.

\section{ENDNOTES}

1 An excerpt of this soundscape is available at http://epress.anu.edu.au/hrj/2007_02/Forgiveness.mp3

For a full profile of the Linen Memorial's evolution and projected presentations, see Trouton's site, http://www.linenmemorial.org/ 